\title{
A Boundary Element Investigation of Liquid Sloshing in Coupled Horizontal and Vertical Excitation
}

\author{
De-Zhi Ning, ${ }^{1,2}$ Wei-Hua Song, ${ }^{1}$ Yu-Long Liu, ${ }^{1}$ and Bin Teng ${ }^{1}$ \\ ${ }^{1}$ State Key Laboratory of Coastal and Offshore Engineering, Dalian University of Technology, \\ Dalian 116024, China \\ ${ }^{2}$ Key Laboratory of Renewable Energy and Gas Hydrate, Chinese Academy of Sciences, \\ Guangzhou 510640, China
}

Correspondence should be addressed to De-zhi Ning, dzning@dlut.edu.cn

Received 24 January 2012; Revised 22 April 2012; Accepted 2 May 2012

Academic Editor: Armin Troesch

Copyright (C 2012 De-zhi Ning et al. This is an open access article distributed under the Creative Commons Attribution License, which permits unrestricted use, distribution, and reproduction in any medium, provided the original work is properly cited.

Sloshing flows in a two-dimensional rigid rectangular tank under specified excitations in the coupled horizontal and vertical modes are simulated by using a higher-order boundary element method (BEM). The liquid sloshing is formulated as an initial-boundary-value problem based on the fully nonlinear potential flow theory. And a semi-mixed Eulerian-Lagrangian technique combined with the 4th-order Runge-Kutta scheme is employed to advance the solutions in the time marching process. A smoothing technique is applied to the free surface at every several time steps to avoid the possible numerical instabilities. Numerical results obtained are compared with the available solutions to validate the developed model. The parametric studies are carried out to show the liquid sloshing effects in terms of the slosh frequencies and excitation amplitudes in horizontal and vertical modes, the second-order resonance frequency, a bottom-mounted vertical rigid baffle, free surface displacement, and hydrodynamic forces acting on the tank.

\section{Introduction}

Liquid sloshing, displaying a free-surface fluctuation in partially filled containers under external excitations, is a known physical phenomenon existing in a variety of engineering applications such as liquid oscillation in large storage tank by earthquake, the motion of liquid fuel in aircraft and spacecraft, the liquid motion in tank, and the water flow on the deck of ship. Such liquid motions may lead to the unexpected instability and failure of engineering structural system. Especially when the excitation stroke is large or the excitation frequency is close to the natural frequency of the container, the caused damage may be a tremendous loss of human, economic, and environmental resources. Thus, it is still urged the need for 
further research on the understanding of the complex sloshing behavior and the technique for sloshing suppression.

Numerous studies related to liquid sloshing have been carried out numerically, theoretically, and experimentally in the past several decades. For example, Faltinsen [1] derived the linear analytical solution of a horizontally excitation tank in 2D. Frandsen [2] obtained the linear and second-order analytical solutions of a fixed tank with initial free surface being cosine curve. Faltinsen et al. [3] performed sloshing experiments in a squarebase tank. Akyildiz and Erdem Ünal [4] made sloshing experiments in a moving tank with different baffle arrangements. Okamoto and Kawahara [5] performed the experiments of liquid sloshing in rectangular and hexagonal tanks. Faltinsen [6] and Nakayama and Washizu [7] adopted the boundary element method to model large amplitude sloshing in a 2D rectangular container subjected to a horizontal excitation. Wu et al. [8] gave an account of both 2D and 3D sloshing problems based on finite element method. Frandsen and Borthwick [9] simulated the sloshing motion in fixed and vertically excited containers using a finite difference solver. Wang and Khoo [10], and Sriram et al. [11] numerically simulated 2D sloshing waves due to random excitation. Eswaran et al. [12] numerically and experimentally studied the sloshing motions in baffled and unbaffled tank subjected to horizontal excitation. Cho et al. [13] investigated the resonant sloshing response in 2D baffled tank by using FEM. Biswal et al. [14] used FEM to compute the nonlinear sloshing response of liquid in a rigid rectangular and cylindrical tank with horizontal baffle. Panigrahy et al. [15] experimentally researched hydrodynamic pressure developed on the tank with horizontal and vertical baffles subjected to horizontal excitation. Liu and Lin [16] adopted VOF method to simulate liquid sloshing in 3D rectangular baffled tank. Belakroum et al. [17] studied the vibratory behaviors of three different configurations of tanks equipped with baffles to predict the damping effect of baffles on sloshing in tank. In addition, Ortiz et al. [18-21] founded a powerful closed-form model to study the coupling of nonlinear liquid sloshing and the container motion, in which the fluid is modeled using a 2D BEM based on potential flow theory with modified Rayleigh damping, the container boundary can be arbitrarily curved, and the container motion can be induced by a flexible multibody system.

As an extension of the previous studies, the liquid sloshing in a 2D tank with and without a vertical baffle, subjected to the coupled horizontal and vertical excitations, are numerically investigated by a fully nonlinear higher-order boundary element method. The effects of two excitations and bottom-mounted vertical baffle on the nonlinear liquid sloshing are further researched. The relating studies are still limited. This paper is organized as follows. The mathematical formulation is firstly given in Section 2. Then, in Section 3, the present numerical results including wave surface and hydrodynamic pressure are compared with analytical solutions, published experimental data, and numerical results to validate the proposed model. In Section 4, liquid sloshing in a 2D tank without baffle subjected to the coupled horizontal and vertical excitations is firstly considered. The effect of excitation frequencies and intensities on liquid sloshing is studied. Next, liquid sloshing in baffled tank is considered to analyze the effect of baffle position and dimension on wave surface and wave forces. Finally, conclusions are given in Section 5.

\section{Mathematical Formulation}

Referring to Figure 1, liquid sloshing in a rectangular tank with length $L$ and water depth $H$ is considered in the present study. Two Cartesian coordinate systems, including a space-fixed 


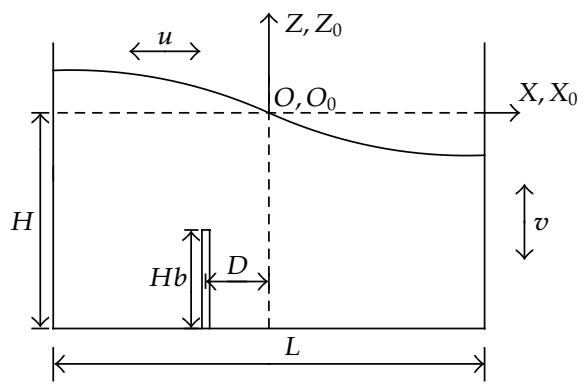

Figure 1: Definition sketch.

coordinate $O_{0} X_{0} Z_{0}$ and a tank-fixed coordinate $O X Z$, are defined with $Z$ and $Z_{0}$ positive upwards. The two systems coincide with each other when the tank is at rest.

The displacement of tank is defined as $X_{b}=\left[x_{b}(t), z_{b}(t)\right]$ in coordinate $O_{0} X_{0} Z_{0}$. Under the assumptions that fluid motion is irrotational and fluid is incompressible and inviscid, the fluid motion is, therefore, governed by Laplace equation:

$$
\nabla^{2} \phi=0
$$

where $\phi$ is the velocity potential. The following condition is satisfied on the interface of tank and liquid:

$$
\frac{\partial \phi}{\partial n}=U \cdot n
$$

where $U=d X_{b} / d t$ is the velocity of the tank and $n$ is the outward vector normal to the tank walls. On the instantaneous free surface $z_{0}=\eta_{0}\left(x_{0}, t\right)$, both the fully nonlinear dynamic and kinematic boundary conditions are satisfied:

$$
\begin{aligned}
& \frac{\partial \phi}{\partial t}+\frac{1}{2} \nabla \phi \cdot \nabla \phi+g \eta_{0}=0, \\
& \frac{\partial \eta_{0}}{\partial t}+\frac{\partial \phi}{\partial x_{0}} \frac{\partial \eta_{0}}{\partial x_{0}}-\frac{\partial \phi}{\partial z_{0}}=0
\end{aligned}
$$

where $\eta_{0}$ is free surface and $g$ is gravity acceleration. 
By using the following (2.4) and (2.5), the (2.3) can be transformed into (2.6) and (2.7) in the moving system $O X Z$ :

$$
\begin{gathered}
\nabla_{x_{0} z_{0}}=\nabla_{x z} \\
\left(\frac{\partial}{\partial t}\right)_{x_{0} z_{0}}=\left(\frac{\partial}{\partial t}-\frac{d X_{b}}{d t} \cdot \nabla\right)_{x z}, \\
\frac{\partial \phi}{\partial t}-\nabla \phi \cdot \frac{d X_{b}}{d t}+\frac{1}{2} \nabla \phi \cdot \nabla \phi+g\left(\eta+z_{b}\right)=0, \\
\frac{\partial \eta}{\partial t}+\left(\frac{\partial \phi}{\partial x}-\frac{d x_{b}}{d t}\right) \frac{\partial \eta}{\partial x}-\left(\frac{\partial \phi}{\partial z}-\frac{d z_{b}}{d t}\right)=0,
\end{gathered}
$$

where $\eta=\eta_{0}-z_{b}$ is the free surface in coordinate system $O X Z$ for fixed $x$. A semi-mixed Eulerian-Lagrangian technique is adopted to change the potential with time on the free surface as follows:

$$
\frac{\delta \phi[x, \eta(x, t), t]}{\delta t}=\frac{\partial \phi}{\partial t}+\frac{\partial \phi}{\partial z} \frac{\partial \eta}{\partial t}
$$

Thus dynamic boundary condition is written as

$$
\frac{\delta \phi}{\delta t}+\frac{\partial \phi}{\partial z} \frac{\partial \eta}{\partial t}-\nabla \phi \cdot \frac{d X_{b}}{d t}+\frac{1}{2} \nabla \phi \cdot \nabla \phi+g\left(\eta+z_{b}\right)=0
$$

The velocity potential $\phi$ can be split as follows in the space-fixed system:

$$
\phi=\varphi+x u+z v
$$

where $u$ and $v$ are the components of $U$ at $x$ and $z$ directions, respectively. Substituting (2.10) into (2.1), (2.2), (2.7), and (2.9), we can obtain

$$
\begin{gathered}
\nabla^{2} \varphi=0 \\
\frac{\partial \varphi}{\partial n}=0 \\
\frac{\partial \eta}{\partial t}=-\frac{\partial \varphi}{\partial x} \frac{\partial \eta}{\partial x}+\frac{\partial \varphi}{\partial z}, \\
\frac{\delta \varphi}{\delta t}=\frac{\partial \varphi}{\partial z} \frac{\partial \eta}{\partial t}-\frac{1}{2} \nabla \varphi \cdot \nabla \varphi-g \eta-x \frac{d u}{d t}-\eta \frac{d v}{d t} .
\end{gathered}
$$

The initial condition $\phi=0$ is written as

$$
\varphi(x, z, 0)=-x u(0)-z v(0) .
$$

The initial free surface $\eta(x, 0)$ is fixed according to practical simulation. 
In addition, hydrodynamic pressure acting on tank can be obtained by Bernoulli equation in space-fixed coordinate $O_{0} X_{0} Z_{0}$

$$
P=-\rho\left(\frac{\partial \phi}{\partial t}+\frac{1}{2} \nabla \phi \cdot \nabla \phi+g \eta\right)
$$

Through (2.4), (2.5) and (2.10), (2.13) is transformed in tank-fixed coordinate OXZ

$$
P=-\rho\left(\frac{\partial \varphi}{\partial t}+\frac{1}{2} \nabla \varphi \cdot \nabla \varphi+g \eta+x \frac{\partial u}{\partial t}+z \frac{\partial v}{\partial t}\right)
$$

Then, the force acting on tank can be obtained by integration and the time derivative of velocity potential, that is, first term in (2.14), is obtained by the acceleration potential method.

The direct boundary integral equation is derived to solve the prescribed boundary value problem by using the second Green's theorem [22]. Applying the Green function satisfying the impermeable condition on the sea bed, integral equation can be written as

$$
C(p) \varphi(p)=\int_{\Gamma}\left(\varphi(p) \frac{\partial G(p, q)}{\partial n}-G(p, q) \frac{\partial \varphi(q)}{\partial n} d \Gamma\right),
$$

where $p$ and $q$ are source and field points, and $C$ is the solid angle which can be conveniently and economically computed by the indirect method in the present study [23]. $\Gamma$ is liquid domain boundary including free surface boundary and solid boundary and $G$ is a simple Green function and is written as follows:

$$
G(p, q)=\frac{1}{2 \pi}\left(\ln r_{1}+\ln r_{2}\right),
$$

where $r_{1}=\sqrt{\left(x-x_{0}\right)^{2}+\left(z-z_{0}\right)^{2}}, r_{2}=\sqrt{\left(x-x_{0}\right)^{2}+\left(z+z_{0}+2 H\right)^{2}}$, and $H$ is water depth.

Then the boundary surface is discretized with a number of three-node line elements. The geometry of each element is represented by the quadratic shape functions, thus the entire curved boundary can be approximated by a number of higher-order elements. Within the boundary elements, physical variables are also interpolated by the same shape functions, that is, the elements are isoparametric. Then the discretized integral equation can be written as linear equation systems:

$$
\left[\begin{array}{ll}
\mathrm{A}_{11} & \mathrm{~A}_{12} \\
\mathrm{~A}_{21} & \mathrm{~A}_{22}
\end{array}\right]\left\{\begin{array}{l}
\left.\varphi\right|_{\text {on solid surfaces }} \\
\left.\frac{\partial \varphi}{\partial n}\right|_{\text {on free surface }}
\end{array}\right\}=\left\{\begin{array}{l}
\mathrm{B}_{1} \\
\mathrm{~B}_{2}
\end{array}\right\} .
$$

The discretized integral equation is reformulated at each time step, as the nodes are moved vertically and the grid is updated by stretching. For the sake of better stability and convenience, the 4th-order Runge-Kutta scheme is used at each time step. The methodology for obtaining the velocity components of the nodes, the updated position of the free surface, and the updated velocity potential is the same as described by Ning and Teng [24]. As the 
proposed container is a rectangular one, it is quite easy to use the five-point smoothing technique on the instantaneous free surface at every several time steps to prevent the socalled saw-tooth instabilities when some steeper waves are simulated. The detail can also be referred to Ning et al. [25]. For the container with curved boundaries, it is advised to use the smoothing and volume-correction techniques under polar coordinate system described by Ortiz and Barhorst [19].

\section{Numerical Validations}

In this section, the present model will be validated through comparing the computed wave surface and hydrodynamic pressure with analytical solution, published experimental data, and numerical results. A tank with and without baffle will be considered, respectively. The natural modes of a rectangular tank can be obtained by solving a linearized natural sloshing standing wave problem. And the natural frequency can be expressed as

$$
\omega_{n}=\sqrt{g \frac{n \pi}{L} \tanh \left(\frac{n \pi}{L} H\right)},
$$

where $n=1,2,3$ and so on.

\subsection{Validation of Wave Surface}

Simulation of liquid sloshing in a rectangular tank without baffle is the first benchmark validation test. A tank subjected to pure horizontal excitation $x_{b}(t)=A \sin (\omega t)$ is considered. The dimensions of the tank are taken as $L=2.0 \mathrm{~m}$ and $H=1.0 \mathrm{~m}$. The initial wave surface is supposed to be stable. Through numerical convergence test, the temporal and spatial steps are selected as $\Delta t=0.01 \mathrm{~s}$ and $\Delta x=\Delta z=0.05 \mathrm{~m}$. Figure 2 presents the distributions of wave profile measured from the bottom of the tank at two dimensionless time $t /(h / G)^{0.5}=13.0667$ and $t /(h / G)^{0.5}=15.725$ for $A=0.0186 \mathrm{~m}$ and $\omega=0.999 \omega_{1}$. The comparisons among experimental data [26], results from finite element method [8], and present numerical results are also shown. It can be seen that the numerical simulation gives good agreement with experimental data and FEM results.

The second set of validation tests is concerned with a tank subjected to pure vertical excitation. The tank scale is $L / H=2.0$. The vertical excitation is $z_{b}(t)=A_{v} \cos \left(\omega_{v} t\right)$, where $A_{v}$ and $\omega_{v}$ are the amplitude and frequency of vertical excitation, respectively. The initial wave surface is taken as $\eta(x, 0)=a \cos (\pi x / L)$. Parameter $k_{v}=A_{v} \omega_{v}{ }^{2} / g$ is used as a measure of the intensity of vertical excitation and $\varepsilon=a \omega_{1}^{2} / g$ is defined as a measure of wave profile nonlinearity. Figure 3 shows the comparison of wave surface time history at the left tank wall between the present and finite difference [2] numerical results in the condition of $\varepsilon=0.0014$ (i.e., $a=0.00049 \mathrm{~m}$ ), $\omega_{v}=0.8 \omega_{1}$, and $k_{v}=0.5$ (i.e., $A_{v}=0.27 \mathrm{~m}$ ). It is found that present results have good agreement with Frandsen's [2] result.

Further, liquid sloshing induced by coupled horizontal and vertical excitation is studied. The dimension of the tank is the same as the above case. Horizontal excitation and vertical excitation are taken as $x_{b}(t)=A_{h} \cos \left(\omega_{h} t\right)$ and $z_{b}(t)=A_{v} \cos \left(\omega_{v} t\right)$. Parameter $k_{h}=A_{h} \omega_{h}{ }^{2} / g$ is used as a measure of the intensity of horizontal excitation. In this condition, initial wave surface can be taken as $\eta(x, 0)=0$. Figure 4 shows the comparison of time histories of wave surface at the left tank wall between present and Frandsen's [2] result in 


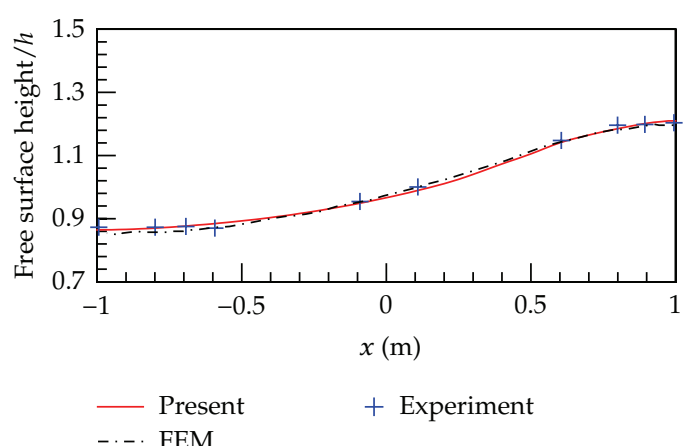

(a) $t /(h / G)^{0.5}=13.0667$

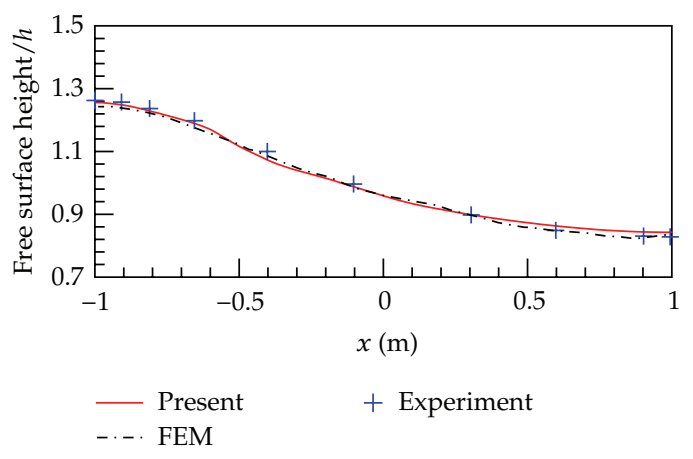

(b) $t /(h / G)^{0.5}=15.725$

Figure 2: Distribution of free surface elevation at two times.

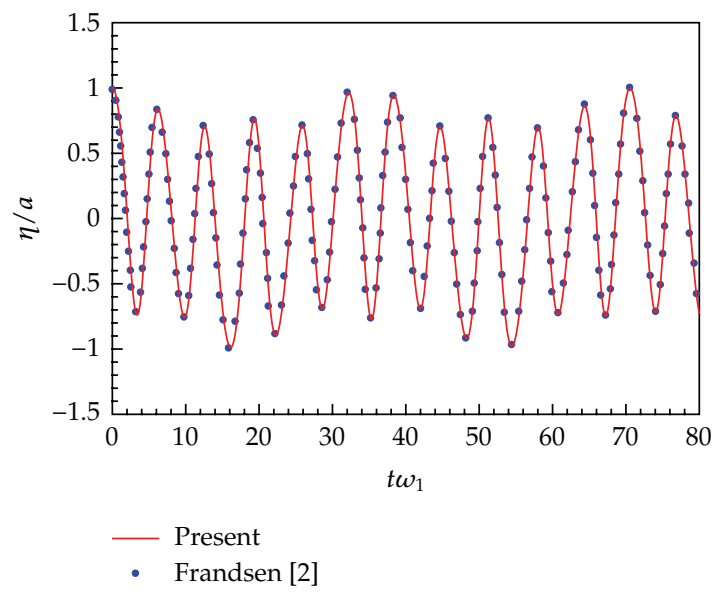

Figure 3: Time history of wave surface at the left tank wall due to vertical excitation.

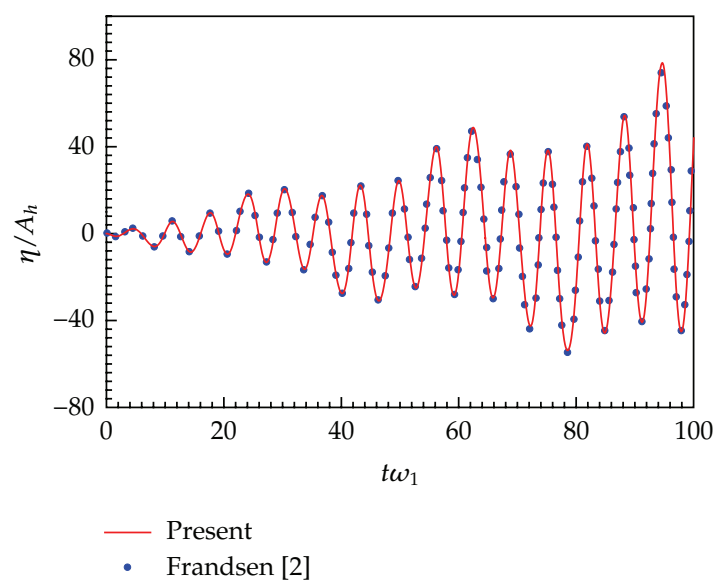

Figure 4: Time history of wave surface at the left tank wall due to coupled horizontal and vertical excitation. 
the condition of $\omega_{h}=0.98 \omega_{1}, \omega_{v}=0.8 \omega_{1}, k_{h}=0.0014$, and $k_{v}=0.5$ (i.e., $A_{h}=0.0005 \mathrm{~m}$, $A_{v}=0.27 \mathrm{~m}$ ). It can be seen that there still is a good agreement between two methods.

Another case for liquid forced sloshing in a tank with a vertical baffle is investigated. The tank $(L / H=2.0)$ is assumed to move as $X(t)=a \sin \omega t$. Excitation amplitude and frequency is $a=0.002 \mathrm{~m}$ and $\omega=5.29 \mathrm{rad} / \mathrm{s}$ ( $\omega$ is near first-order natural frequency of tank without baffle). A vertical baffle with $\mathrm{Hb}=0.75 \mathrm{H}$ and $B=0.01 \mathrm{~m}$ is arranged at the center of tank bottom. Figure 5 shows the comparison of the time histories of wave surface at the right wall and the comparison between the present method and VOF method [16]. From the figure, it can be seen that the results of both methods are in good agreement and wave surface does not resonate due to the vertical baffle. Baffle changes the natural frequency of the tank and makes present natural frequency away from external excitation frequency to restrain liquid sloshing. Figure 6 shows the comparison of the first-order natural frequency of tank with different baffle length between present result and the linear frequency-domain result [27]. It is found that they coincide with each other well and the longer the baffle is, the smaller the natural frequency becomes, that is, far away from that of the unbaffled tank.

\subsection{Validation of Hydrodynamics}

Firstly, a tank without baffle $(L / H=2.0)$ is forced to move as $X(t)=a \sin \omega t$ and excitation amplitude and frequency is $a=0.00186 \mathrm{~m}$ and $\omega=5.3 \mathrm{rad} / \mathrm{s}$. Because movement amplitude $a$ is very small, the liquid sloshing can be considered as a linear problem. Figure 7 shows the comparisons of hydrodynamic pressures between the present results and linear analytical solutions [8] at free surface and tank bottom of the left tank wall. It can be found that the present results and linear analytical solution have a good agreement and the hydrodynamic pressure trends to be resonant.

A tank with $L=30 \mathrm{~m}$ and depth $H=15 \mathrm{~m}$, moving as $X(t)=-a \cos \omega t(a=0.5 \mathrm{~m}$, $\omega=0.628 \mathrm{rad} / \mathrm{s}$ ), is further considered. The tank motion is stopped after $5 \mathrm{~s}$ and the inner liquid begins to slosh freely. Figure 8 shows the time histories of horizontal wave force acting on the tank with and without vertical baffle. The vertical baffle with $\mathrm{Hb}=9.0 \mathrm{~m}$ is arranged at center of tank bottom. In the two figures, it is obvious that the present results and those obtained from FEM [28] coincide with each other very well and the wave force is lower significantly due to the effect of the vertical baffle. It also can be seen from the figure that both the horizontal wave loads have a sudden decrease at $t=5 \mathrm{~s}$ due to the tank motion stopped at the moment.

Through the above examples, the present numerical model is verified to be accurate to simulate liquid sloshing due to coupled horizontal and vertical excitations in a tank with and without vertical baffle.

\section{Results and Discussion}

In this section, liquid sloshing subjected to coupled horizontal and vertical excitation, with and without a vertical baffle, will be systematically investigated. The width and liquid depth in the tank are defined as $L=1.0 \mathrm{~m}$ and $H=0.5 \mathrm{~m}$, respectively. The horizontal and vertical excitations are taken as $x_{b}(t)=A_{h} \cos \left(\omega_{h} t\right)$ and $z_{b}(t)=A_{v} \cos \left(\omega_{v} t\right)$, respectively. $A_{h}$ and $A_{v}$ are excitation amplitude. $\omega_{h}$ and $\omega_{v}$ are excitation frequency. Parameters $k_{h}=A_{h} \omega_{h}^{2} / g$ and $k_{v}=A_{v} \omega_{v}^{2} / g$ are used as a measure of the intensity of the horizontal and vertical excitations, respectively. The initial wave surface is always supposed to be zero. 


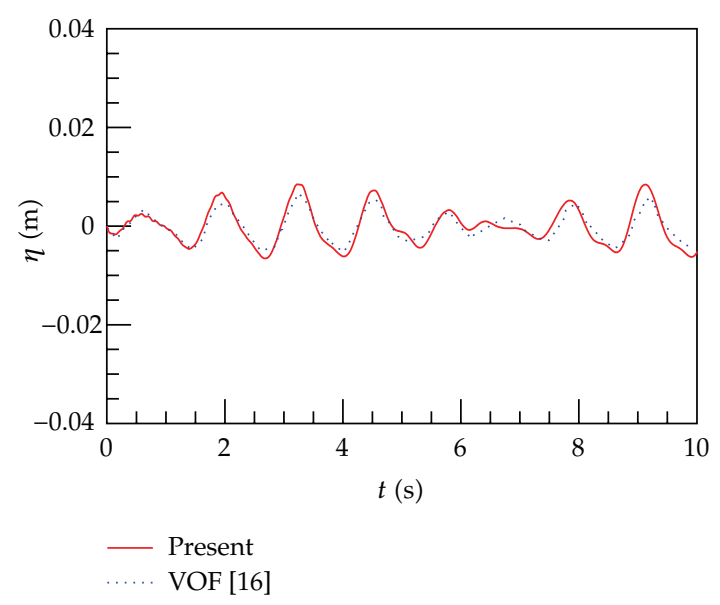

Figure 5: Time history of wave surface at the right tank wall with a vertical baffle.

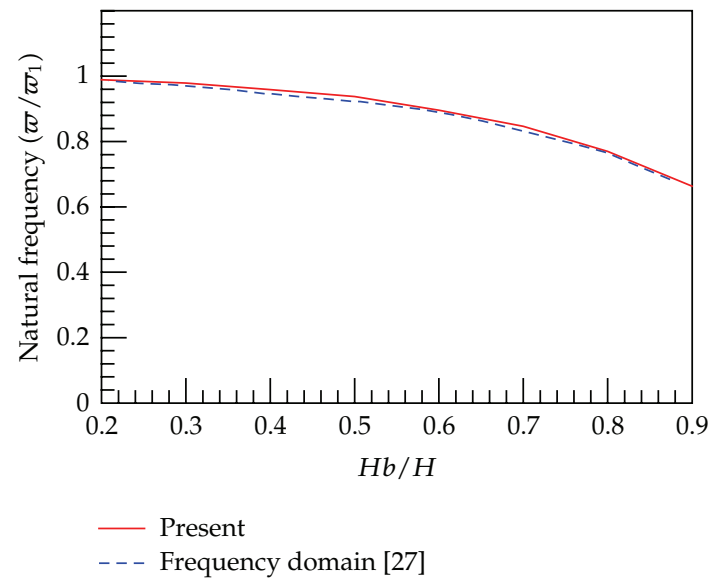

Figure 6: Distribution of the first-order natural frequency for different baffle length.

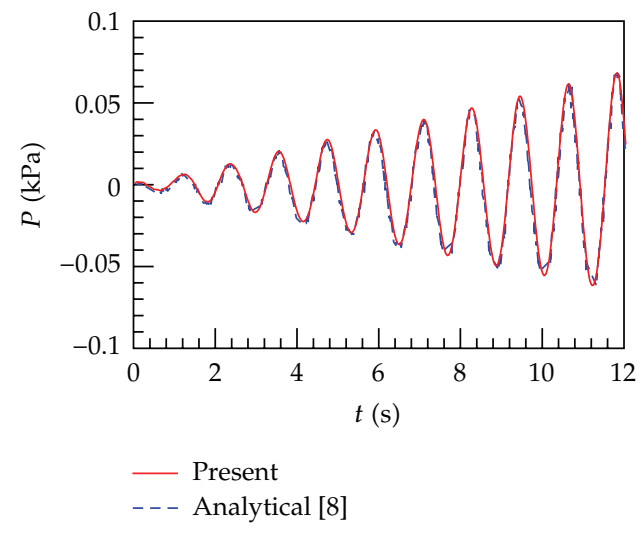

(a) at the free surface $(-L / 2.0, \eta)$

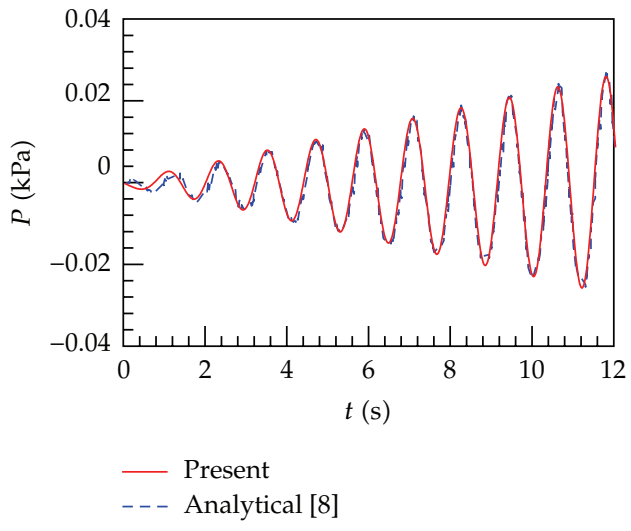

(b) at the tank bottom $(-L / 2.0,-H)$

Figure 7: Time histories of hydrodynamic pressure at the free surface and tank bottom of the left tank wall. 


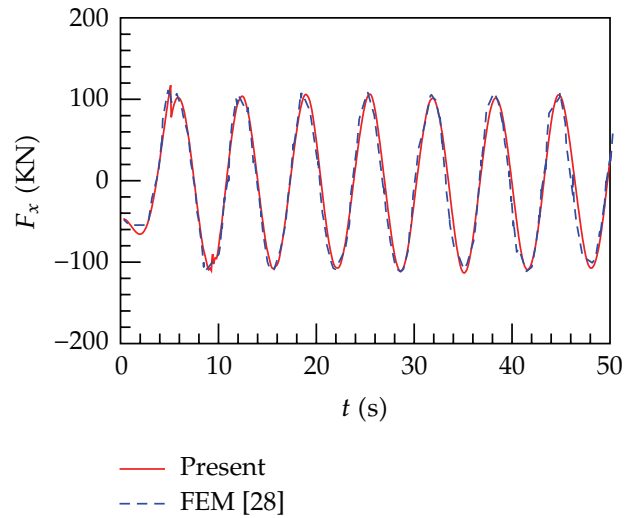

(a) without baffle

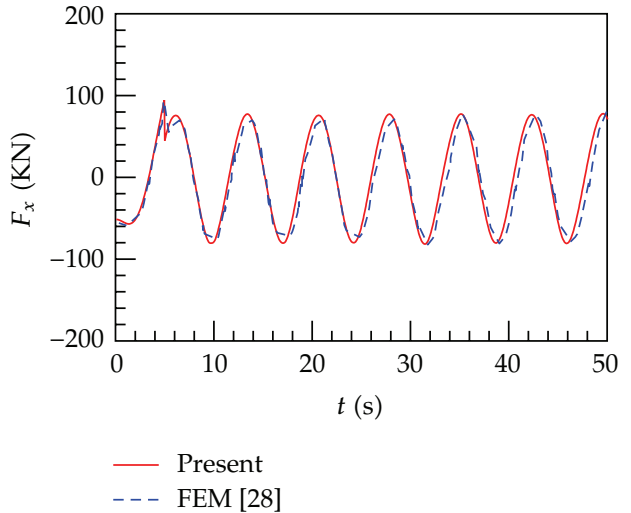

(b) with baffle

Figure 8: total horizontal hydrodynamic pressure time history with and without vertical baffle.

\subsection{Effects of Horizontal and Vertical Excitation Frequencies on Liquid Sloshing}

As it is well known, liquid sloshing is most violent when external frequency approaches to natural frequency. Therefore, three cases are considered for the external excitation frequencies separately or both equal to natural frequency. Case A is that parameters $\omega_{h}=\omega_{v}=\omega_{1}, k_{h}=$ 0.003 , and $k_{v}=0.2$ (i.e., $A_{h}=0.001 \mathrm{~m}$ and $A_{v}=0.069 \mathrm{~m}$ ) are taken. Case B is that $\omega_{h}=$ $\omega_{1}, \omega_{v}=0.7 \omega_{1}, k_{h}=0.003$, and $k_{v}=0.2$ (i.e., $A_{h}=0.001 \mathrm{~m}$ and $A_{v}=0.142 \mathrm{~m}$ ) are defined. Case $C$ is that $\omega_{h}=0.7 \omega_{1}, \omega_{v}=\omega_{1}, k_{h}=0.0014$, and $k_{v}=0.2$ (i.e., $A_{h}=0.001 \mathrm{~m}$ and $A_{v}=$ $0.069 \mathrm{~m}$ ) are chosen. Through numerical convergence test, temporal step is selected as $\Delta t=$ $0.012 \mathrm{~s}$ and spatial step is defined as $\Delta x=\Delta z=0.05 \mathrm{~m}$. Figure 9 shows time histories of wave surface at the left tank wall and the corresponding spectral charts obtained by FFT method. From the figure, It can be seen that the resonance phenomena occur as shown in Figures 9(a) and 9 (c) when the horizontal excitation frequency is equal to natural frequency. Horizontal excitation plays a dominated role on the shape and peak amplitude of wave surface and can be always found in the spectral charts. However, the vertical excitation frequency does not exist alone in spectral chart and occurs as the forms of sum- and difference-frequency with horizontal excitation frequency. Meanwhile, the first-order natural frequency $\omega_{1}$ and second harmonic frequency $2 \omega_{1}$ are also invoked and obviously seen in the spectral charts as shown in Figures 9(a), 9(c), and 9(f).

\subsection{Effects of Horizontal and Vertical Excitation Intensities on Liquid Sloshing}

As the excitation intensity is directly related to the sloshing nonlinearity, the effects of horizontal and vertical excitation intensities will be investigated in this section. The excitation intensity is measured by the corresponding parameter, namely, $k_{h}=A_{h} \omega_{h}{ }^{2} / g$ and $k_{v}=$ $A_{v} \omega_{v}{ }^{2} / g$, in the present study.

Firstly, the effect of horizontal excitation intensity is studied. Given $\omega_{h}=0.7 \omega_{1}, \omega_{v}=$ $1.2 \omega_{1}, k_{v}=0.2$ (i.e., $A_{v}=0.048 \mathrm{~m}$ ), the horizontal excitation intensity parameter $k_{h}$ is taken as 0.0014 and 0.021 corresponding to small and large excitation amplitude of $A_{h}=0.001 \mathrm{~m}$ 


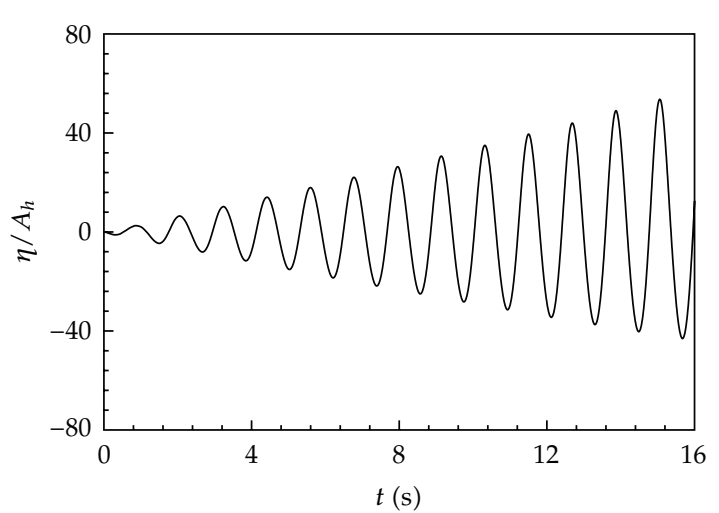

(a) Time histories of wave surface for case A $\left(\omega_{h}=\omega_{v}=\omega_{1}\right)$

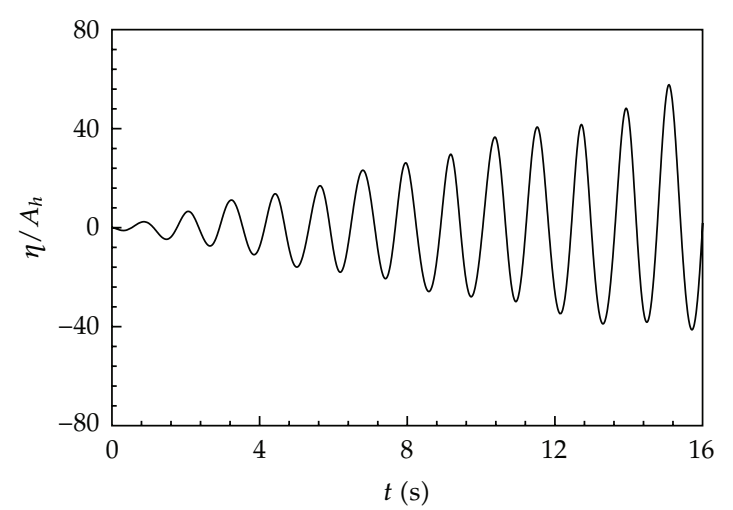

(c) Time histories of wave surface for case B $\left(\omega_{h}=\omega_{1}, \omega_{v}=\right.$ $\left.0.7 \omega_{1}\right)$

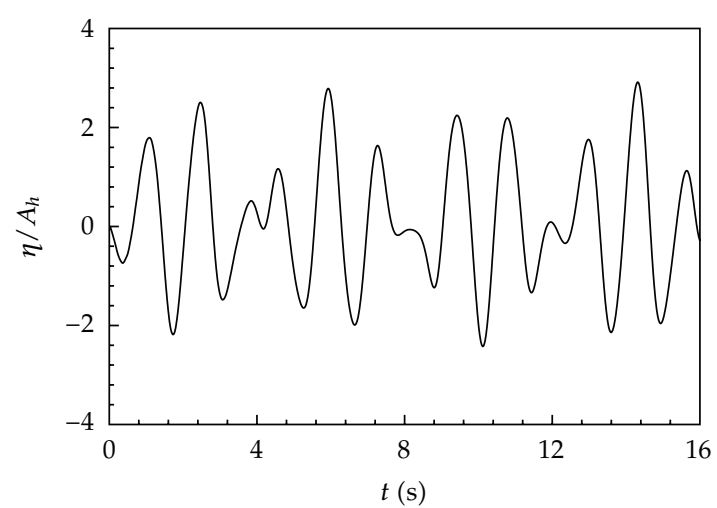

(e) Time histories of wave surface for case $\mathrm{C}\left(\omega_{h}=\right.$ $\left.0.7 \omega_{1}, \omega_{v}=\omega_{1}\right)$



(b) Spectral chart for Case A $\left(\omega_{h}=\omega_{v}=\omega_{1}\right)$

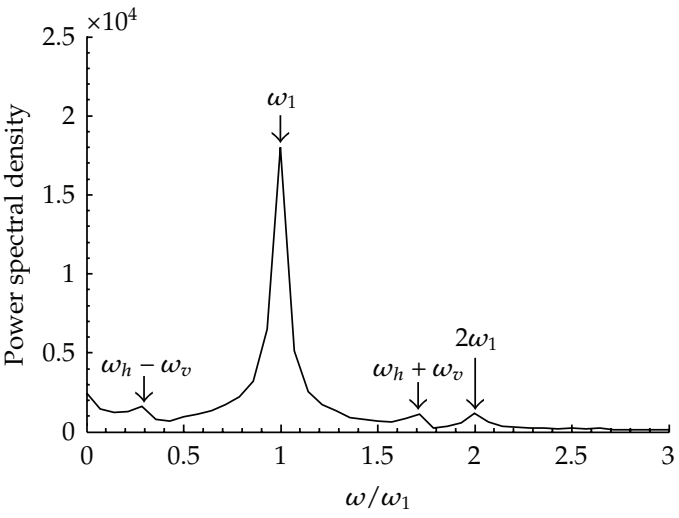

(d) Spectral chart for case B $\left(\omega_{h}=\omega_{1}, \omega_{v}=0.7 \omega_{1}\right)$

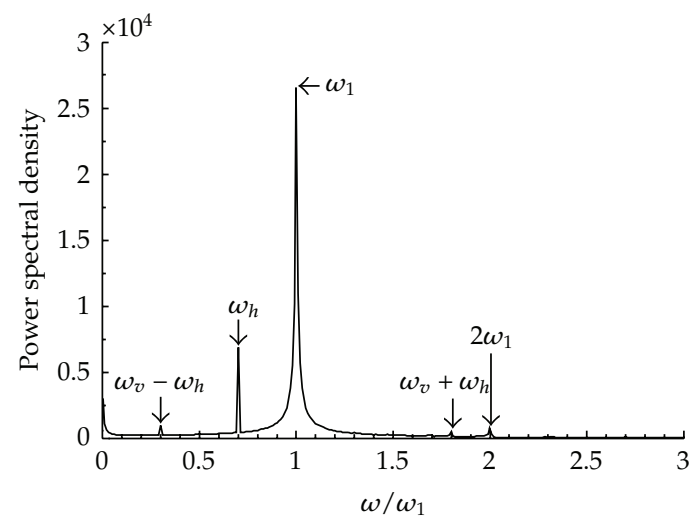

(f) Spectral chart for case C $\left(\omega_{h}=0.7 \omega_{1}, \omega_{v}=\omega_{1}\right)$

Figure 9: Time histories of wave surface at the left tank wall and the corresponding spectral charts.

and $0.015 \mathrm{~m}$, respectively. Figure 10 illustrates the comparison of time series of wave surface at the left tank wall. From the figure, it can be seen that the wave phases are same for two cases but the wave nonlinearity is more apparent for the larger $k_{h}\left(k_{h}=0.021\right)$, namely, 


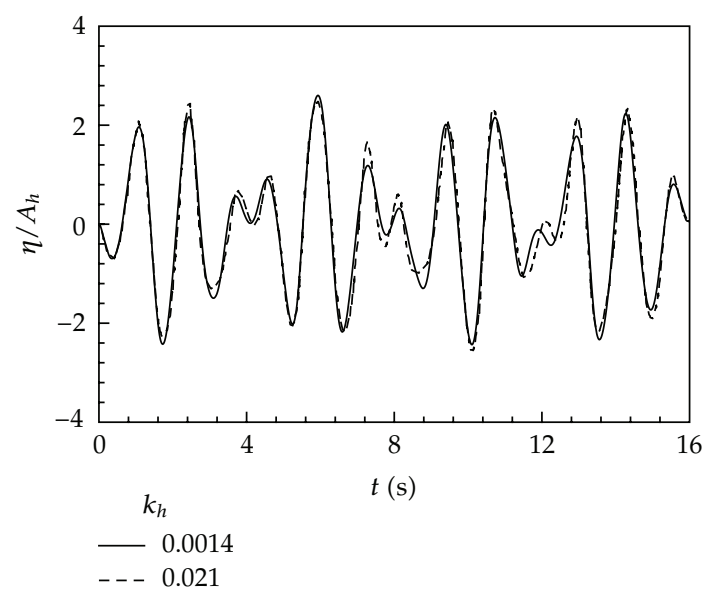

Figure 10: Time histories of wave surface at the left tank wall for $k_{h}=0.0014$ and 0.021 .

higher and narrower wave crests, and flatter and lower wave troughs. Then, the FFT method is adopted to analyze time histories of wave surface shown in Figure 10, and the corresponding spectral charts are presented in Figure 11. It displays two dominating frequencies of which one is equivalent to the horizontal excitation frequency $\omega_{h}$, and the other is first-order natural frequency $\omega_{1}$. Their values in Figure 11(b) are larger than those in Figure 11(a) due to larger excitation intensity $k_{h}$. More additional frequencies related to small spectral value, such as $\omega_{1}-\omega_{h}, \omega_{1}+\omega_{h}, 2 \omega_{1}$ and $\omega_{3}$ are also induced by the stronger nonlinearity as shown in Figure 11(b).

Then, in order to investigate the effect of vertical excitation intensity, two cases with $\omega_{h}=0.7 \omega_{1}, \omega_{v}=0.8 \omega_{1}, k_{h}=0.0014, k_{v}=0.01$ and 0.1 (i.e., $A_{h}=0.001 \mathrm{~m}, A_{v}=0.005 \mathrm{~m}$ and $0.05 \mathrm{~m}$ ) are chosen. Figures 12 and 13 show the time histories of wave surface at the left tank wall for these two cases and the corresponding spectral charts. From the figures, it is found that although vertical excitation amplitude $A_{v}$ increases ten times from $0.005 \mathrm{~m}$ to $0.05 \mathrm{~m}$, the intensity of liquid sloshing does not increase accordingly and the wave surface value is only a little different, which is also represented in the corresponding spectral charts. The horizontal excitation frequency and first-order natural frequency are still the dominating frequencies. Thus it can be obtained that the effect of vertical excitation to liquid sloshing is weaker than that of horizontal excitation. But it has to be noticed that the sum-frequency and differencefrequency between horizontal frequency and vertical frequency occur due to the increase of vertical excitation intensity $k_{v}$.

\subsection{Second-Order Resonance of Liquid Sloshing}

Generally, the resonant phenomena can be excited when the excitation frequency is near to the odd natural frequencies of the container, but it is opposite for the even natural frequencies. Most previous researches were still limited to the first-order resonance problem, except that $\mathrm{Wu}$ (2007) [29] analytically studied the second-order resonance of sloshing due to half excitation frequency, sum-frequency, or difference-frequency equal to the even mode natural frequency. In this section, the second-order resonance of sloshing, excited by half second-order natural frequency, is numerically simulated and the relation with water depth is 


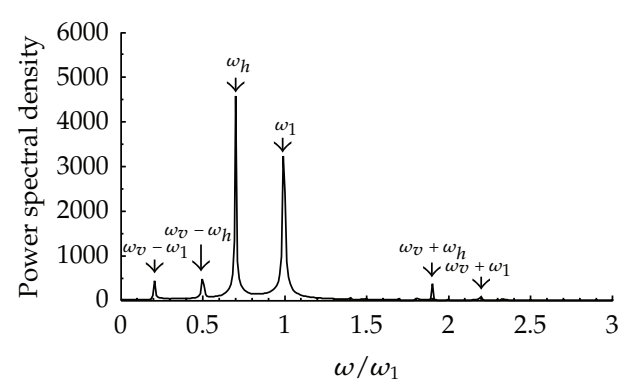

(a) $k_{h}=0.0014$

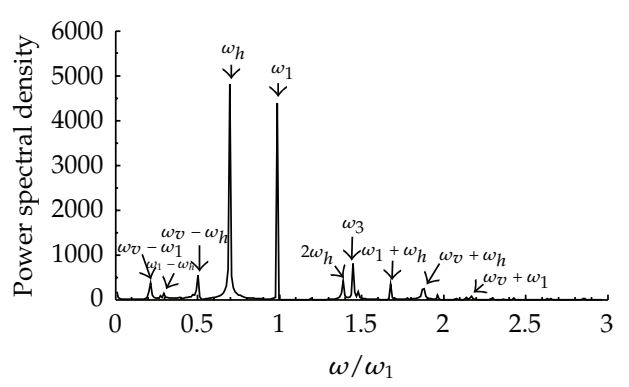

(b) $k_{h}=0.021$

Figure 11: Spectral charts corresponding to the Figure 10.

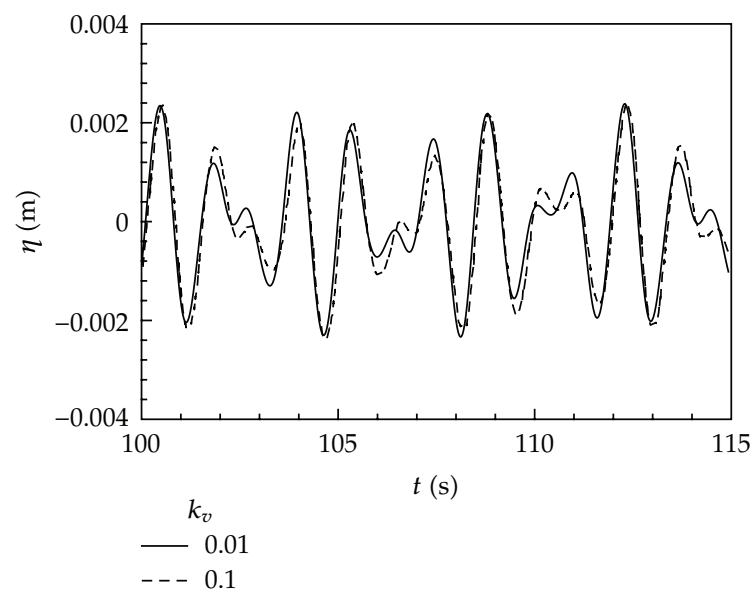

Figure 12: Time histories of wave surface at the left tank wall for $k_{v}=0.01$ and 0.1 .

studied. As an example, a 1 m-length tank motion is governed by $x_{b}(t)=A_{h} \cos \left(\omega_{h} t\right)$, where $A_{h}=0.001 \mathrm{~m}$ and $\omega_{h}$ is taken as $0.5 \omega_{2}$. Water depth $H$ is defined as $0.2 \mathrm{~m}, 0.3 \mathrm{~m}, 0.4 \mathrm{~m}$, and $0.5 \mathrm{~m}$, respectively. According to (3.1), the corresponding second-order natural frequency $\omega_{2}$ can be obtained as $7.238 \mathrm{rad} / \mathrm{s}, 7.671 \mathrm{rad} / \mathrm{s}, 7.798 \mathrm{rad}$, and $7.835 \mathrm{rad} / \mathrm{s}$, respectively. Figure 14 shows the time histories of wave surface at left tank wall and the corresponding spectrum distribution for these four conditions. From the figure, it can be seen that liquid sloshing tends to resonance by time even if the excitation frequency is off natural frequency, especially for shallow water depth. Besides the first-order natural frequency, the second-order natural frequency is also provoked under such outer excitation. Both natural frequencies $\omega_{1}$ and $\omega_{2}$ are dominated in liquid sloshing compared with the excitation $0.5 \omega_{2}$, which coincides with the phenomenon of liquid resonance. The more shallow the water depth is, the more contribution of the second-order natural frequency results in, and the more violent the sloshing resonance is.

\subsection{Effects of a Bottom-Mounted Vertical Baffle on Liquid Sloshing}

Baffle is a kind of passive method to restrain liquid sloshing and has been applied in engineering widely. Many researchers have investigated liquid sloshing in baffled tank, 


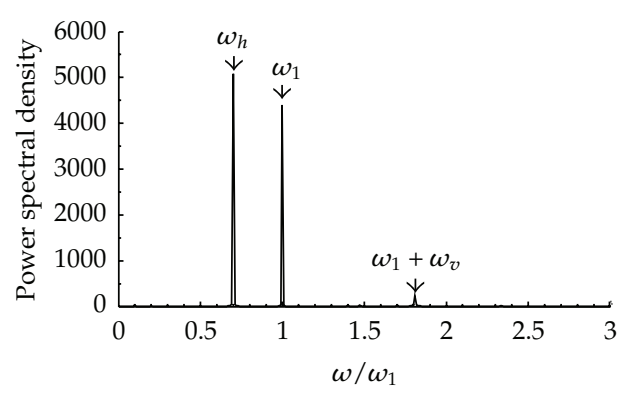

(a) $k_{v}=0.01$

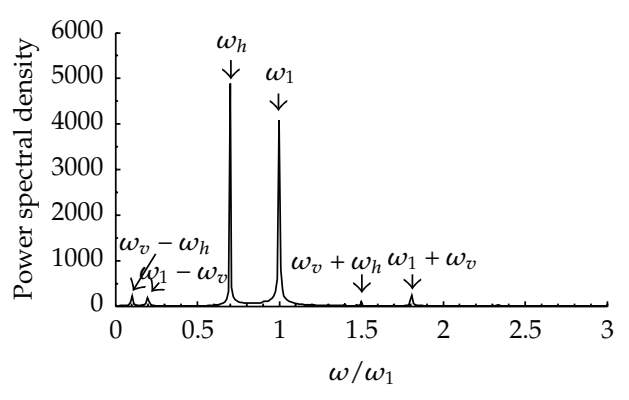

(b) $k_{v}=0.1$

Figure 13: Spectral charts corresponding to the Figure 12.

but most of them supposed the tank is subjected to pure horizontal excitation. In fact, the tank movement is complicated and can be considered coupled movement of some basic movements. Thus, the effects of a vertical baffle on liquid sloshing are investigated comprehensively. Wave surface and wave force are chosen to reflect the corresponding effects. The same tank dimensions and motion are taken the same as the above case. An example of $\omega_{h}=\omega_{v}=\omega_{1}, k_{h}=k_{v}=0.0029$ (i.e., $A_{h}=A_{v}=0.001 \mathrm{~m}$ ) is considered in this section.

The effect of baffle position is firstly investigated. A vertical baffle of $0.4 \mathrm{~m}$ length (i.e., $\mathrm{Hb}=0.8 \mathrm{H}$ ) is arranged at the tank bottom (as shown in Figure 1). The thickness of the baffle is taken as $0.01 \mathrm{~m}$ and is supposed to be rigid. Figure 15 shows time histories of wave surface at the left and right walls versus varying baffle position $D$. It is observed that the closer to the center the vertical baffle is, the smaller is the wave surface. In other words, vertical baffle at center is most efficient to retrain liquid sloshing, which coincides with the common sense. Figure 16 shows the time histories of the total horizontal and vertical wave forces acting on the tank. It is obvious that the closer to the center the vertical baffle is, the smaller the total horizontal wave force is, which coincides with the conclusion of Figure 13. However, the total vertical wave force remains unchanged for different positions of the baffle.

The natural frequency of the above proposed tank will be different due to the presence of vertical baffle at the bottom. Figure 17 shows the time histories of wave surface at the left tank wall in condition of different baffle positions under the excitations of various first-order natural frequencies and the motion governed by $x_{b}(t)=A_{h} \cos \left(\omega_{h} t\right)$, in which $A_{h}=0.001 \mathrm{~m}$ and $\omega_{h}$ is defined as the first-order natural frequency $\omega_{1}$, the baffle length $H b$ is taken as $0.75 \mathrm{H}$, and baffle position $D$ is taken as $0,0.2 \mathrm{~L}$, and $0.4 \mathrm{~L}$, respectively. Based on the linear frequency-domain theory, the corresponding first-order natural frequency $\omega_{1}$ can be obtained as $4.342 \mathrm{rad} / \mathrm{s}, 4.581 \mathrm{rad} / \mathrm{s}$ and $5.134 \mathrm{rad} / \mathrm{s}$, respectively. From the figure, it can be seen that the resonance phenomena still occur under the excitation of natural frequency as that without vertical baffle. However, for the smaller $D$, the sloshing waves propogate more slowly and the resonance amplitudes are also smaller, which presents a better effect on restraining sloshing.

Furthermore, baffle length is also an important factor to influence liquid sloshing. In this part, a vertical baffle with varying length is arranged at the tank bottom-center. Figure 18 presents time histories of wave surface at the left tank wall for three conditions of $\mathrm{Hb}=0.4 \mathrm{H}$, $H b=0.6 H$, and $H b=0.8 H$. When baffle length is $0.4 H$, liquid sloshing is affected a little and wave surface is still near to resonant status. For a baffle of $H b=0.6 H$, wave surface becomes smaller obviously. When baffle length is increased to $0.8 \mathrm{H}$, wave surface stabilizes at a small value. Meanwhile, with the increase of baffle length, the period of liquid sloshing becomes 
Journal of Applied Mathematics

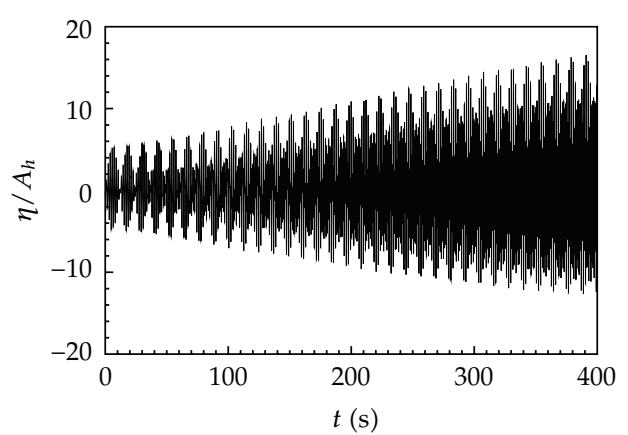

(a) Time history of wave surface at left tank wall for $H=0.2 \mathrm{~m}$

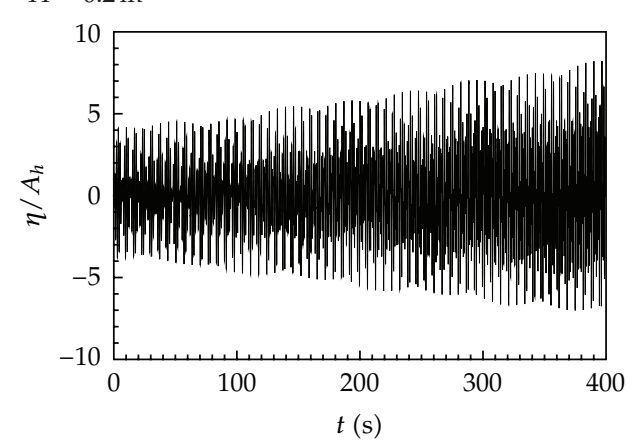

(c) Time history of wave surface at left tank wall for $H=0.3 \mathrm{~m}$

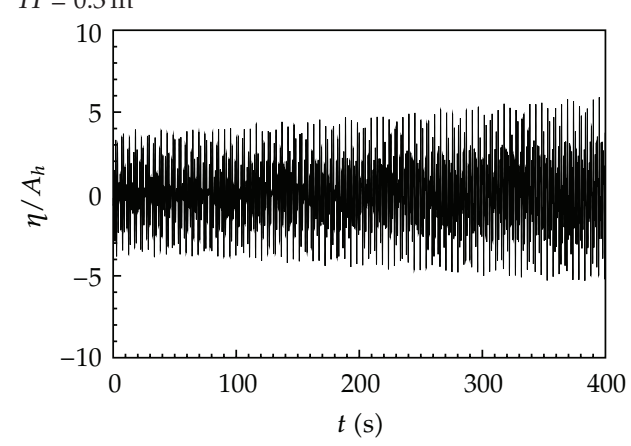

(e) Time history of wave surface at left tank wall for $H=0.4 \mathrm{~m}$

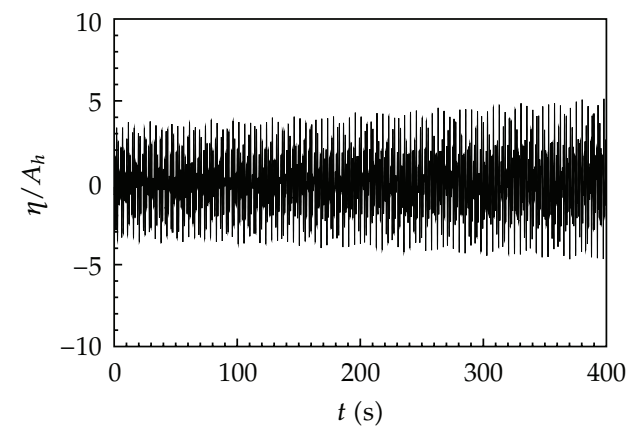

(g) Time history of wave surface at left tank wall for $H=0.5 \mathrm{~m}$

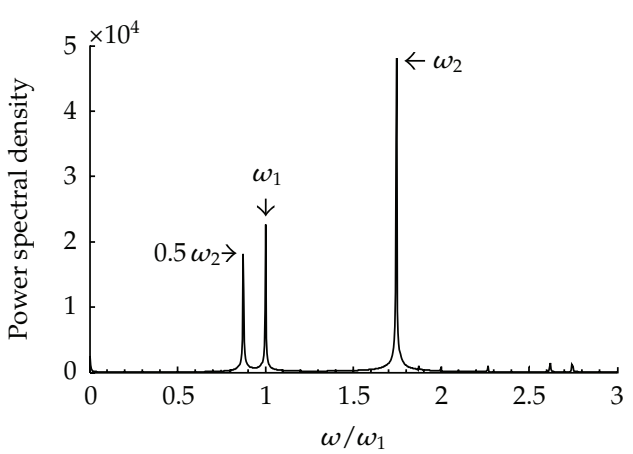

(b) Spectral chart of Figure 14(a)

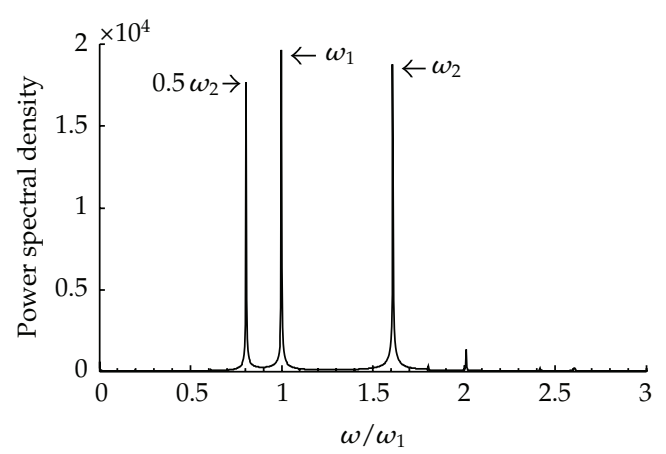

(d) Spectral chart of Figure 14(c)

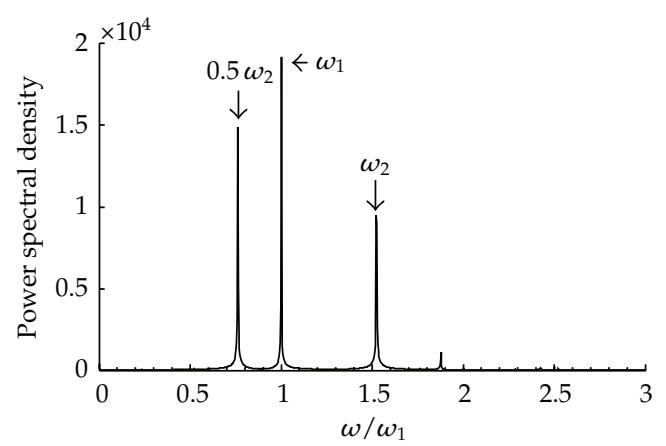

(f) Spectral chart of Figure 14(e)

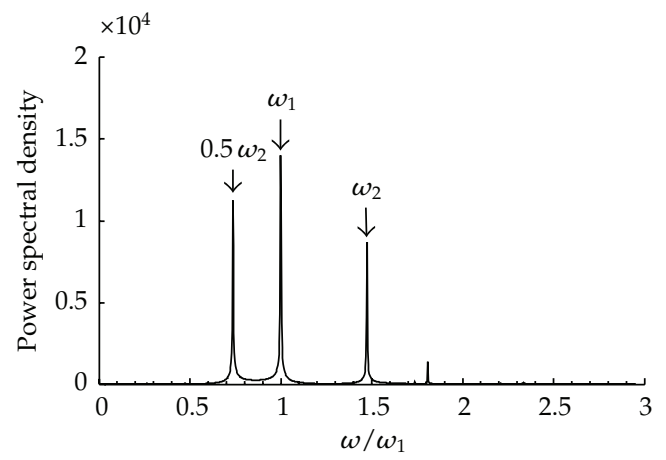

(h) Spectral chart of Figure 14(g)

Figure 14: Time history of wave surface at left tank wall and the spectral charts for excitation frequency $0.5 \omega_{2}$. 


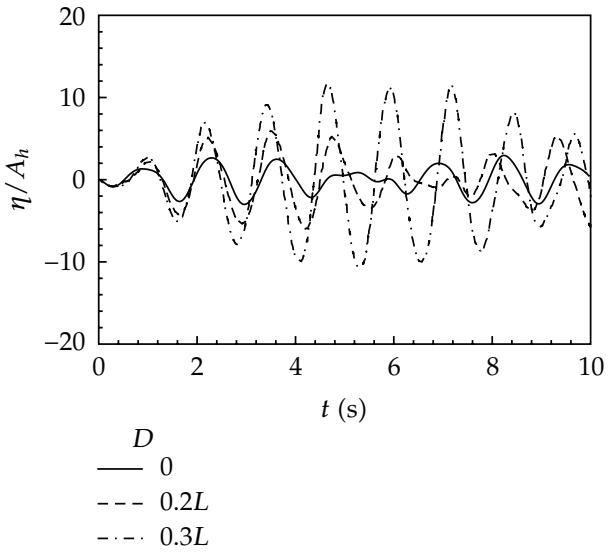

(a) Left wall

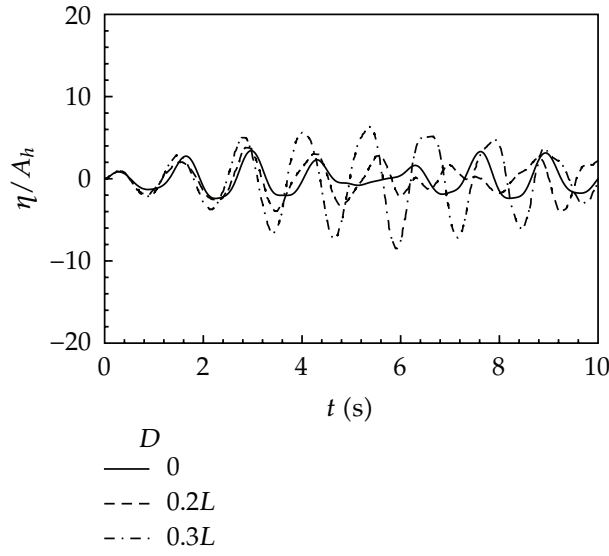

(b) Right wall

Figure 15: Time histories of wave surface at the left and right walls for $H b=0.8 H$.

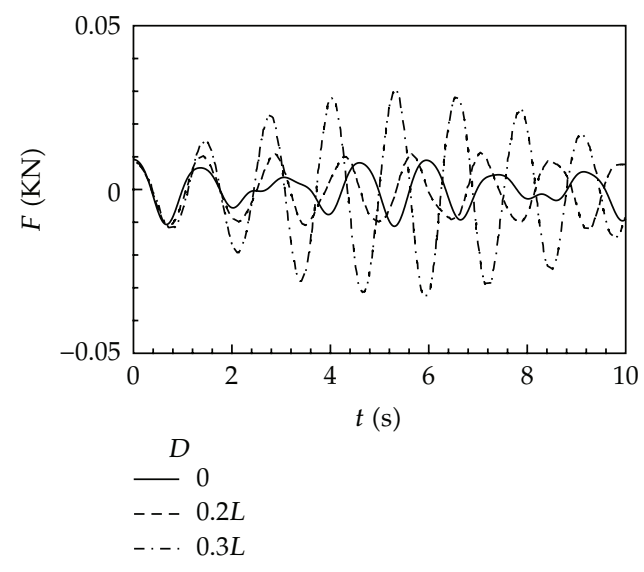

(a) horizontal wave force

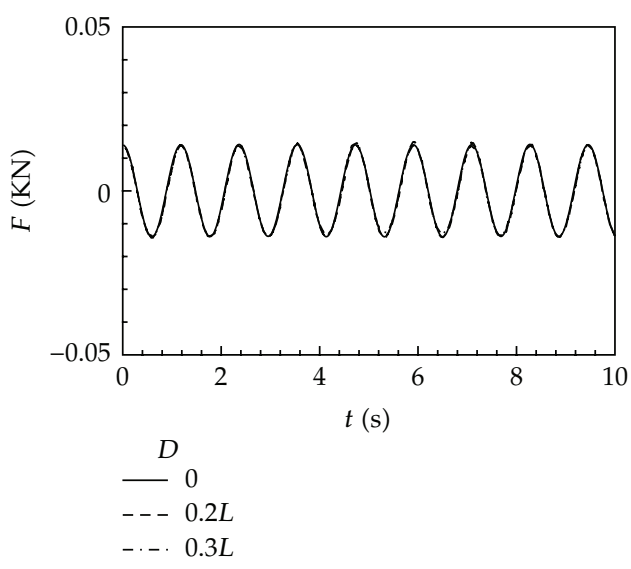

(b) vertical wave force.

Figure 16: Time histories of total horizontal and vertical wave forces for $\mathrm{Hb}=0.8 \mathrm{H}$

longer. Figure 19 shows the time series of total horizontal and vertical wave forces acting on the tank. It is obvious that the longer the vertical baffle is, the smaller is the total horizontal wave force. The total vertical wave force is almost invariant for these three conditions, which is the same as that shown in Figure 16(b).

Next, liquid sloshing in the tank with different baffle length at the corresponding natural frequency is investigated. The baffle is fixed at the middle of tank bottom and baffle length is taken as $0,0.6 \mathrm{H}$, and $0.8 \mathrm{H}$. Based on linear frequency-domain theory, the corresponding first-order natural frequency of tank can be obtained as $5.316 \mathrm{rad} / \mathrm{s}$, $4.757 \mathrm{rad} / \mathrm{s}$, and $4.12 \mathrm{rad} / \mathrm{s}$, respectively. The tank motion is same as that described in Figure 17. Figure 20 gives the time history of wave surface at left tank wall in condition of different baffle lengths. From the figure, the similar conclusions can be obtained as those in Figure 17, that is, for higher $\mathrm{Hb}$, the sloshing waves propogate more slowly, the resonance amplitudes are smaller, and a better effect on restraining sloshing is obtained. 


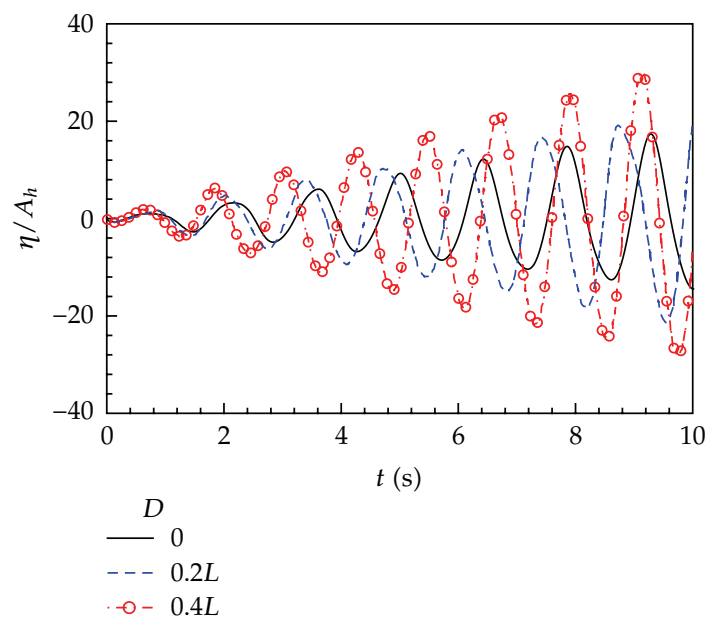

Figure 17: Time history of wave surface at left tank wall under the excitation of natural frequency.

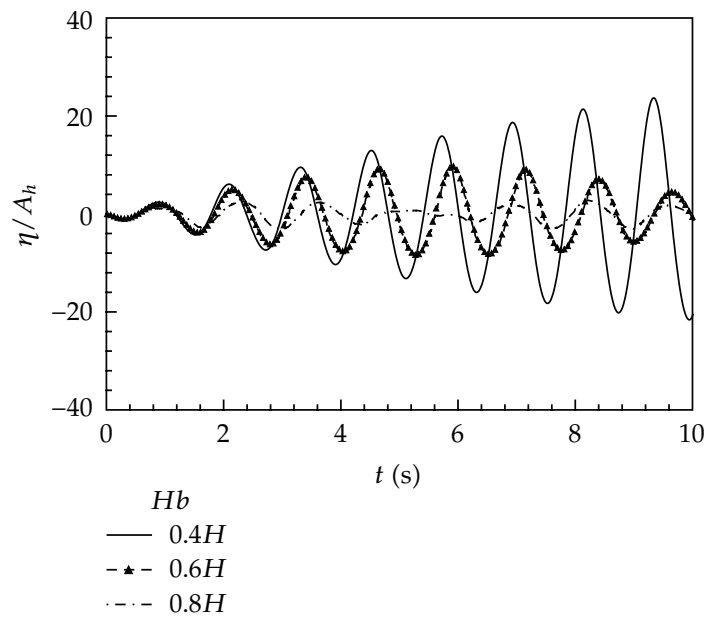

Figure 18: Time histories of wave surface at the left tank wall for $D=0.0$.

\section{Conclusions}

In the present paper, a higher-order boundary element method has been applied for the fully nonlinear numerical simulation of liquid sloshing in a 2D rectangular tank. The proposed numerical scheme has provided good results in comparison with the analytical solution, published numerical results, and experimental data.

On the base of validations, a tank subjected to the coupled horizontal and vertical excitation is investigated for the effects of excitation frequencies and excitation intensities in the horizontal and vertical directions and vertical bottom-mounted baffle on liquid sloshing. The following conclusions can be obtained. Firstly, the horizontal excitation plays a dominated role on the wave shape and wave nonlinearity relative to the vertical excitation in the coupled sloshing problems. However, the latter can invoke more other higher and lower frequencies among natural frequency and base frequencies. Secondly, with the increasing of 


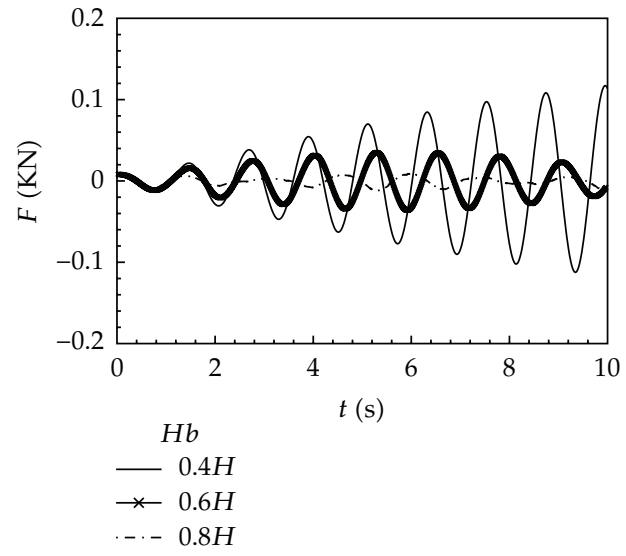

(a) horizontal wave force

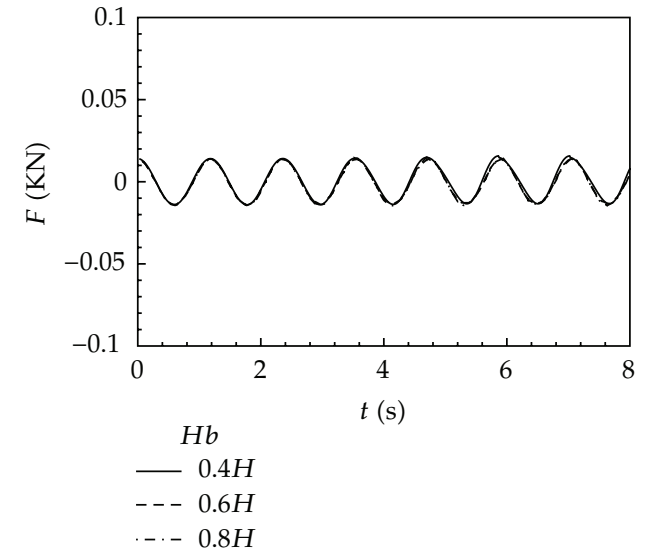

(b) vertical wave force

Figure 19: Time histories of total horizontal and vertical wave forces for $D=0.0$.

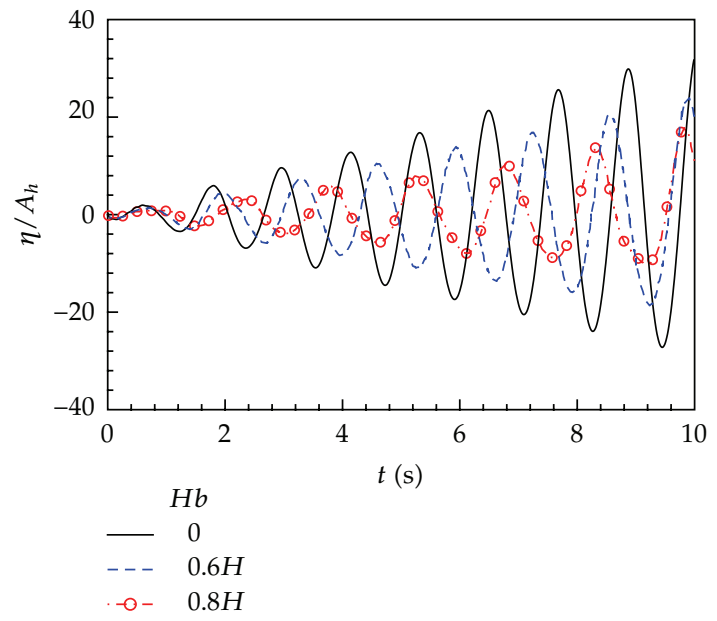

Figure 20: Time history of wave surface at left tank wall under the excitation of first-order natural frequency.

excitation intensities, liquid sloshing becomes more violent and the interaction of frequencies is enhanced. Thus more frequencies are invoked including sum frequency and difference frequency. Last, the vertical bottom-mounted baffle arranged at tank center is most efficient to restrain liquid sloshing due to the natural frequency of the tank changed. Under the excitation of the first-order natural frequency of unbaffled tank, both wave surface and horizontal wave load decrease with the increase of baffle length. However, the vertical baffle does little effect on the vertical wave load.

\section{Acknowledgments}

The authors gratefully acknowledge the financial support from the National Basic Research Program of China (973 Program, Grant no. 2011CB013703), the National Natural Science 
Foundation of China (Grant nos. 51179028 and 50921001), and the Open Fund of Key Laboratory of Renewable Energy and Gas Hydrate, Chinese Academy of Sciences (Grant no. Y007ka).

\section{References}

[1] O. M. Faltinsen, "A nonlinear theory of sloshing in rectangular tanks," Journal of Ship Research, vol. 18, no. 1074, pp. 224-241.

[2] J. B. Frandsen, "Sloshing motions in excited tanks," Journal of Computational Physics, vol. 196, no. 1, pp. 53-87, 2004.

[3] O. M. Faltinsen, O. F. Rognebakke, and A. N. Timokha, "Classification of three-dimensional nonlinear sloshing in a square-base tank with finite depth," Journal of Fluids and Structures, vol. 20, no. 1, pp. 81103, 2005.

[4] H. Akyildiz and N. Erdem Ünal, "Sloshing in a three-dimensional rectangular tank: numerical simulation and experimental validation," Ocean Engineering, vol. 33, no. 16, pp. 2135-2149, 2006.

[5] T. Okamoto and M. Kawahara, "Two-dimensional sloshing analysis by Lagrangian finite element method," International Journal of Numerical Methods in Fluids, vol. 11, no. 5, pp. 453-477, 1990.

[6] O. M. Faltinsen, "A numerical nonlinear method of sloshing in tanks with two dimensional flow," Journal of Ship Research, vol. 22, pp. 224-241, 1978.

[7] T. Nakayama and K. Washizu, "Nonlinear analysis of liquid motion in a container subjected to forced pitching oscillation," International Journal for Numerical Methods in Engineering, vol. 15, no. 8, pp. 12071220, 1980.

[8] G. X. Wu, Q. W. Ma, and R. Eatock Taylor, "Numerical simulation of sloshing waves in a 3D tank based on a finite element method," Applied Ocean Research, vol. 20, no. 6, pp. 337-355, 1998.

[9] J. B. Frandsen and A. G. L. Borthwick, "Simulation of sloshing motions in fixed and vertically excited containers using a 2-D inviscid $\sigma$-transformed finite difference solver," Journal of Fluids and Structures, vol. 18, no. 2, pp. 197-214, 2003.

[10] C. Z. Wang and B. C. Khoo, "Finite element analysis of two-dimensional nonlinear sloshing problems in random excitations," Ocean Engineering, vol. 32, no. 2, pp. 107-133, 2005.

[11] V. Sriram, S. A. Sannasiraj, and V. Sundar, "Numerical simulation of 2D sloshing waves due to horizontal and vertical random excitation," Applied Ocean Research, vol. 28, no. 1, pp. 19-32, 2006.

[12] M. Eswaran, U. K. Saha, and D. Maity, "Effect of baffles on a partially filled cubic tank: numerical simulation and experimental validation," Computers and Structures, vol. 87, no. 3-4, pp. 198-205, 2009.

[13] J. R. Cho, H. W. Lee, and S. Y. Ha, “Finite element analysis of resonant sloshing response in 2-D baffled tank," Journal of Sound and Vibration, vol. 288, no. 4-5, pp. 829-845, 2005.

[14] K. C. Biswal, S. K. Bhattacharyya, and P. K. Sinha, "Non-linear sloshing in partially liquid filled containers with baffles," International Journal for Numerical Methods in Engineering, vol. 68, no. 3, pp. 317-337, 2006.

[15] P. K. Panigrahy, U. K. Saha, and D. Maity, "Experimental studies on sloshing behavior due to horizontal movement of liquids in baffled tanks," Ocean Engineering, vol. 36, no. 3-4, pp. 213-222, 2009.

[16] D. Liu and P. Lin, "Three-dimensional liquid sloshing in a tank with baffles," Ocean Engineering, vol. 36, no. 2, pp. 202-212, 2009.

[17] R. Belakroum, M. Kadja, T. H. Mai, and C. Maalouf, "An efficient passive technique for reducing sloshing in rectangular tanks partially filled with liquid," Mechanics Research Communications, vol. 37, no. 3, pp. 341-346, 2010.

[18] J. L. Ortiz, A. A. Barhorst, and R. D. Robinett, "Flexible multibody systems-fluid interaction," International Journal for Numerical Methods in Engineering, vol. 41, no. 3, pp. 409-433, 1998.

[19] J. L. Ortiz and A. A. Barhorst, "Large-displacement non-linear sloshing in 2-D circular rigid containers-prescribed motion of the container," International Journal for Numerical Methods in Engineering, vol. 41, no. 2, pp. 195-210, 1998.

[20] J. L. Ortiz and A. A. Barhorst, "Closed-form modeling of fluid-structure interaction with nonlinear sloshing: potential flow," AIAA Journal, vol. 35, no. 9, pp. 1510-1517, 1997. 
[21] J. L. Ortiz and A. A. Barhorst, "Modeling fluid-structure interaction," AIAA Journal of Guidance, Control, and Dynamics, vol. 20, no. 6, pp. 1221-1228, 1997.

[22] C. A. Brebbia and S. Walker, Boundary Element Techniques in Engineering, Newnes-Butterworths, 1980.

[23] D.-Z. Ning, B. Teng, H.-T. Zhao, and C.-I. Hao, "A comparison of two methods for calculating solid angle coefficients in a BIEM numerical wave tank," Engineering Analysis with Boundary Elements, vol. 34, no. 1, pp. 92-96, 2010.

[24] D. Z. Ning and B. Teng, "Numerical simulation of fully nonlinear irregular wave tank in three dimension," International Journal for Numerical Methods in Fluids, vol. 53, no. 12, pp. 1847-1862, 2007.

[25] D. Z. Ning, J. Zang, S. X. Liu, R. Eatock Taylor, B. Teng, and P. H. Taylor, "Free-surface evolution and wave kinematics for nonlinear uni-directional focused wave groups," Ocean Engineering, vol. 36, no. 15-16, pp. 1226-1243, 2009.

[26] T. Okamoto and M. Kawahara, "Two-dimensional sloshing analysis by Lagrangian finite element method," International Journal for Numerical Methods in Fluids, vol. 11, no. 5, pp. 453-477, 1990.

[27] Y. S. Choun and C. B. Yun, "Sloshing characteristics in rectangular tanks with a submerged block," Computers and Structures, vol. 61, no. 3, pp. 401-413, 1996.

[28] M. Arafa, "Finite element analysis of sloshing in liquid-filled containers," in Production Engineering and Design for Development (PEDD '07), pp. 793-803, Cairo, Egypt, 2006.

[29] G. X. Wu, "Second-order resonance of sloshing in a tank," Ocean Engineering, vol. 34, no. 17-18, pp. 2345-2349, 2007. 


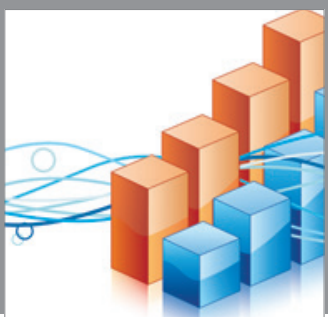

Advances in

Operations Research

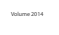

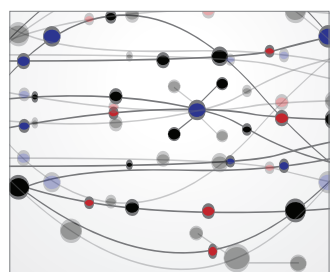

\section{The Scientific} World Journal
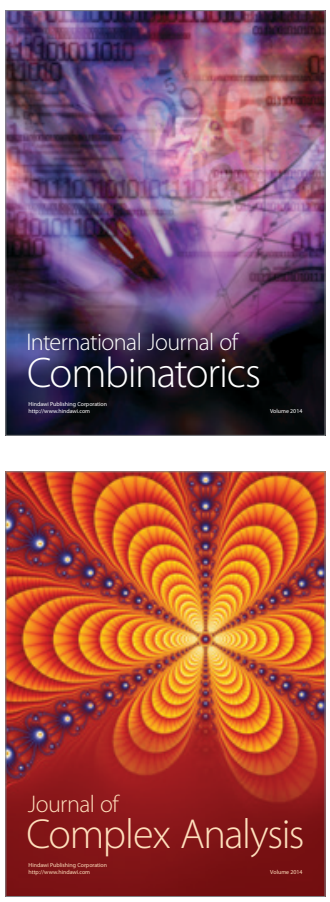

International Journal of

Mathematics and

Mathematical

Sciences
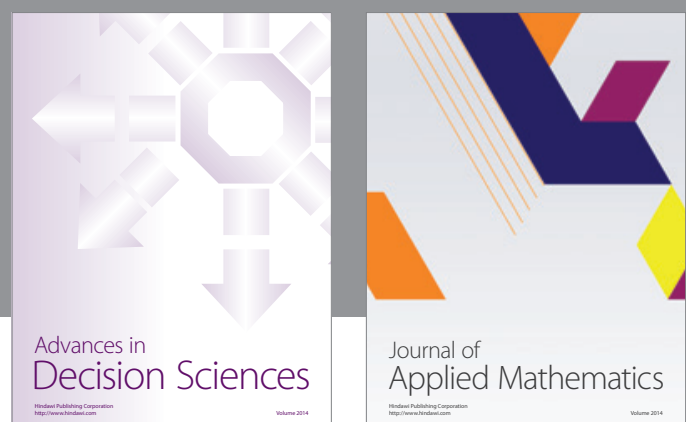

Journal of

Applied Mathematics
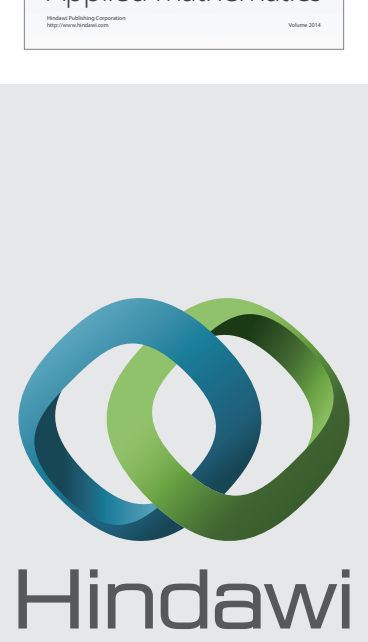

Submit your manuscripts at http://www.hindawi.com
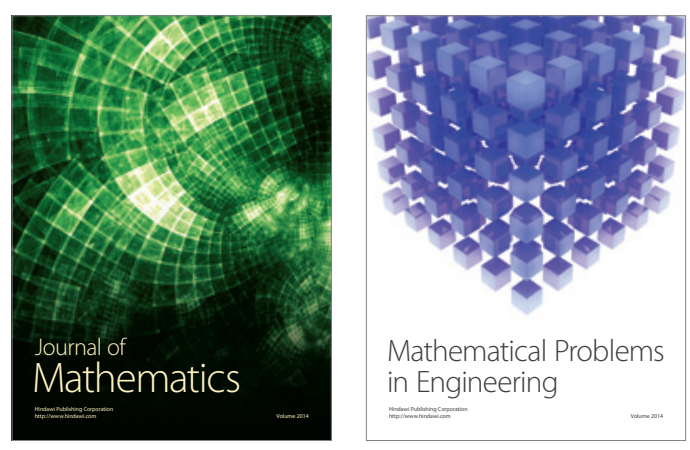

Mathematical Problems in Engineering
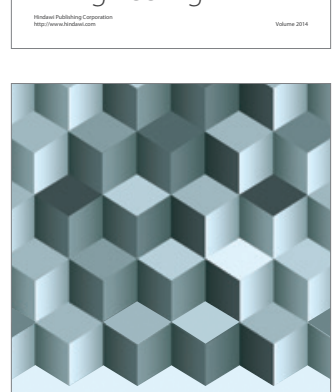

Journal of

Function Spaces
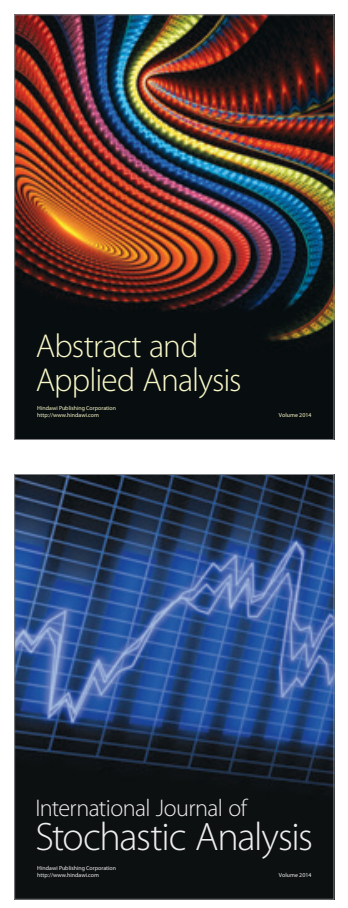

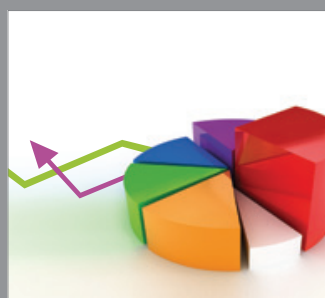

ournal of

Probability and Statistics

Promensencen
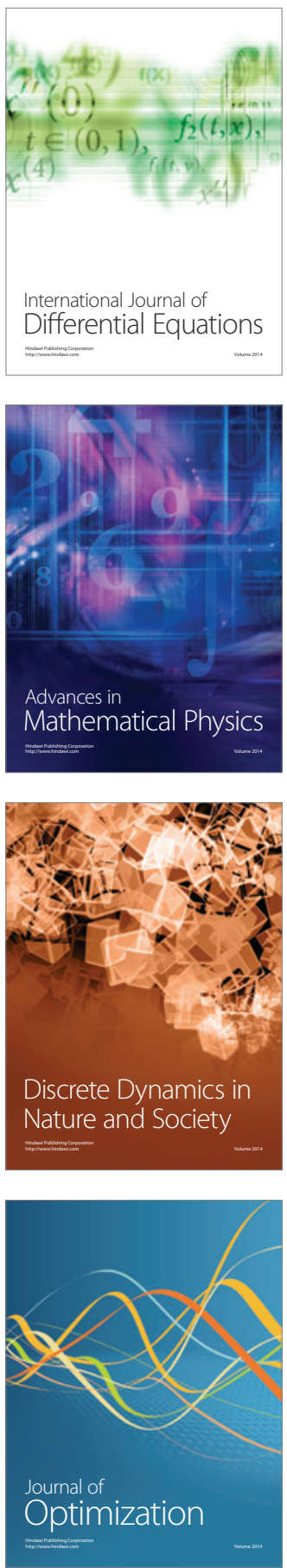